\title{
China: ¿oportunidad o utopía para el crecimiento económico de México y de América Latina?'
}

China: opportunity or utopia for economic growth in Mexico and Latin America?

\section{Sergio E. Martínez Rivera *}

\section{Palabras clave}

Orden económico internacional, Negociaciones comerciales, Actividad económica internacio-

nal, Estudios comparativos por países

Key words

International Economic Order, Trade Negotiations, International Business, Comparative Studies of Countries

JeL

F02, F13, F23, 057
"Prof. Asoc. "C" de tiempo completo. División de Estudios de Posgrado, Facultad de EconomíaUNAM.

1 El presente documento forma parte de los resultados del proyecto de investigación PAPIIT IA303416 "Estudio de la dinámica económica de las economías emergentes desde el Desarrollo Sustentable y la Economía Ecológica: los casos de México, Brasil y China. Se agradece a la DGAPA-UNAM por todo el apoyo brindado para el financiamiento de dicho proyecto.

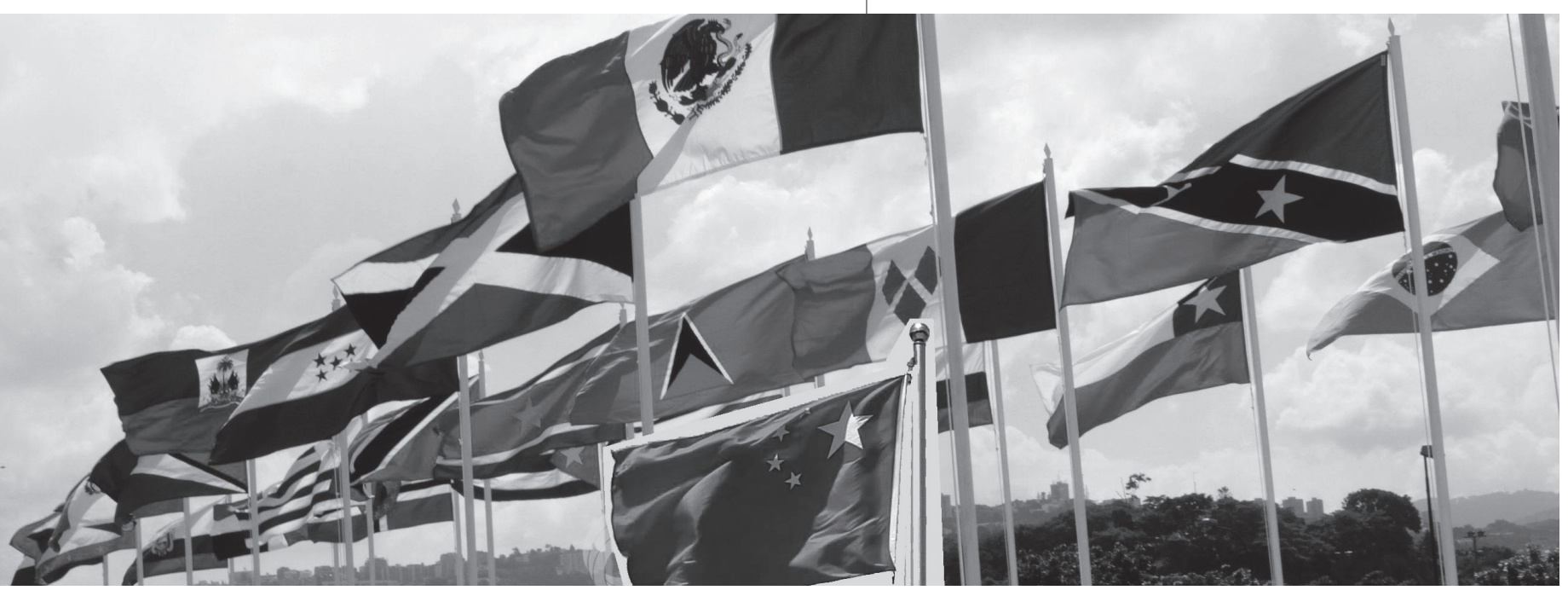




\section{Resumen}

China esta llamado a ser el próximo líder económico mundial en el siglo XxI, esto ha significado que distintos países busquen vincularse con dicha nación para aprovechar el impulso del boom económico que han registrado a lo largo de 30 años y con ello detonar su propio crecimiento. Los gobiernos latinoamericanos en su afán de vincularse con China y aprovechar dicho escenario, desarrollaron una estrategia que predominantemente se orienta a exportar materias primas y recursos naturales a este país asiático y por otro lado, a permitir en sus territorios el desarrollo de infraestructura en materia portuaria y terrestre, energía y minería, entre otras. La forma en que China ha sostenido el crecimiento de su producto no sólo esta basado en medidas netamente económicas sino también demográficas, institucionales y bajo un estricto control del Estado. El modelo de crecimiento chino no puede ser replicado y su dinámica no beneficia de manera homogénea a todas las regiones del planeta. En este sentido América Latina y México tendrán beneficios económicos marginales y de corto plazo si insisten vincularse con China aplicando un modelo primario exportador en vez de aspirar a proyectos de mayor trascendencia.

\section{Abstract}

China is called to be the next world economic leader in the 21st century, this has meant that different countries seek to link with that nation to take advantage of the economic boom they have recorded over 30 years and thereby detonate their own growth. The Latin American governments, in their desire to link with China and take advantage of this scenario, developed a strategy that predominantly aims to export raw materials and natural resources to this Asian country and, on the other hand, to allow in their territories the development of port infrastructure and land, energy and mining, among others. The way in which China has sustained the growth of its product is not only based on purely economic measures but also demographic, institutional and under strict state control. The Chinese growth model can not be replicated and its dynamics do not benefit homogenously all regions of the planet. In this sense Latin America and Mexico will have marginal and short-term economic benefits if they insist on linking to China by applying a primary export model instead of aspiring to projects of greater transcendence.

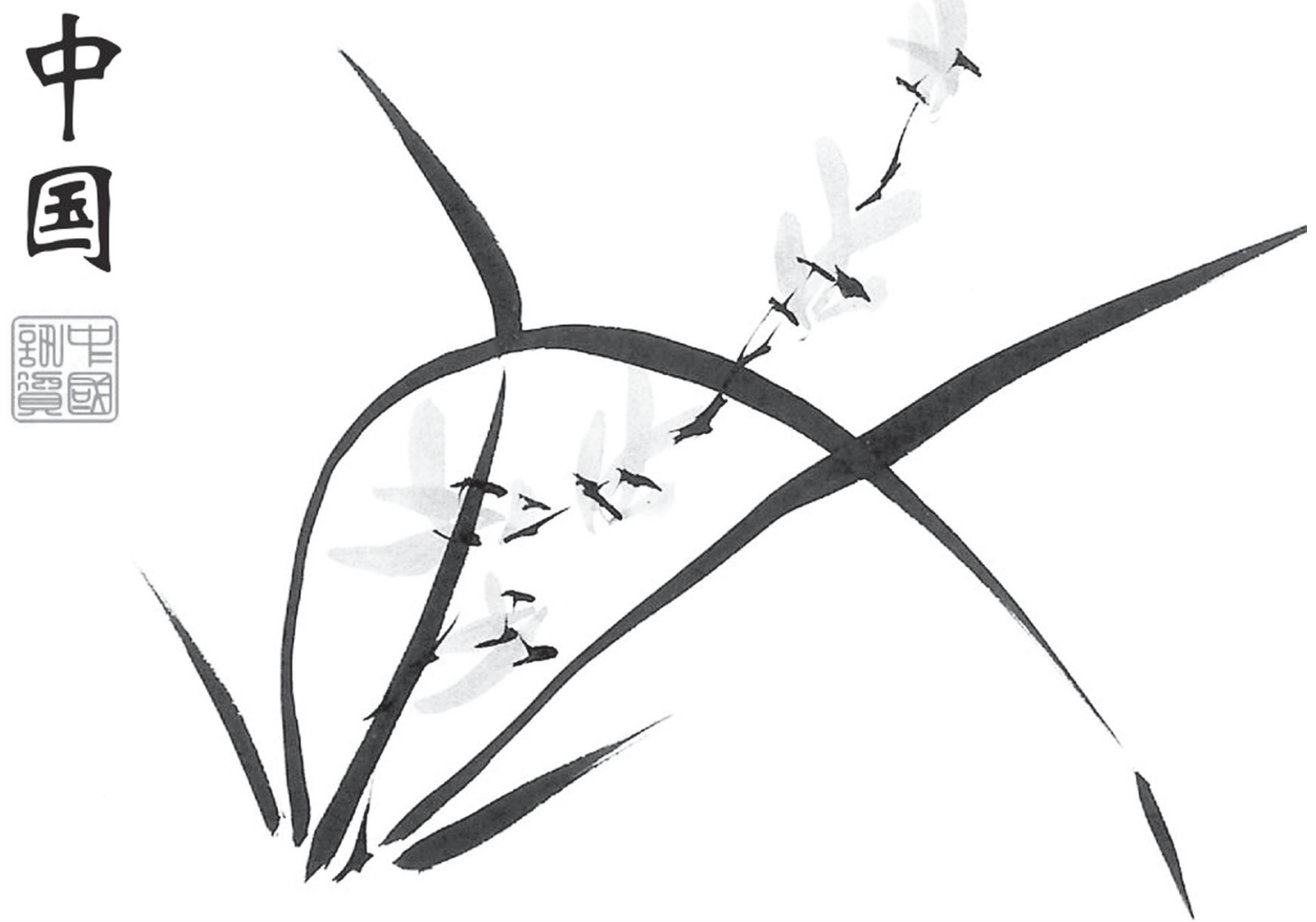


Sergio E. Martínez Rivera | China: ioportunidad para el crecimiento económico de México y de América Latina?

El ascenso económico que ha sostenido China desde 1978 ha convertido a este país en el principal candidato del siglo xxi para reconfigurar el orden económico y político mundial definido décadas atrás por el bloque de países industrializados dentro de los que destacan los Estados Unidos. Dicho papel está sustentado en el crecimiento sostenido de su producto interno bruto (PIB), el cual no sólo es superior al resto de las llamadas economías emergentes sino incluso al resto de los países desarrollados. A esto se suma su consolidación en lo militar, la influencia que esta teniendo internacionalmente en materia geopolítica entre varios aspectos más.

En el presente documento se reflexiona sobre las condiciones básicas que sustentan la dinámica económica de China y sobre el argumento recurrente que se tiene en diversos círculos académicos y empresariales, esto es, ver en el boom económico chino el parteaguas para que América Latina y El Caribe (ALC) y, en este caso México puedan impulsar su crecimiento. Por un lado, porque se interpreta que el país asiático en cuestión representa un amplio mercado en expansión así como de capital disponible y por otro, porque ha puesto en marcha un amplio espectro de estrategias materializadas en proyectos sectoriales y de infraestructura, ciencia y tecnología, etc. Que a decir de algunos, deberían ser replicados.

El tema es por demás pertinente ya que en el ámbito académico y político existe una visión reduccionista y determinística sobre el papel de China y su influencia en la dinámica económica del mundo, en este caso con ALC y México. Es decir, es erróneo suponer que con mayores volúmenes de inversión y de comercio exterior la expansión per se estaría garantizada. Además de se demuestra no comprender la realidad y antecedentes de China, de sus condiciones estructurales en el plano social, político, territorial, etc.

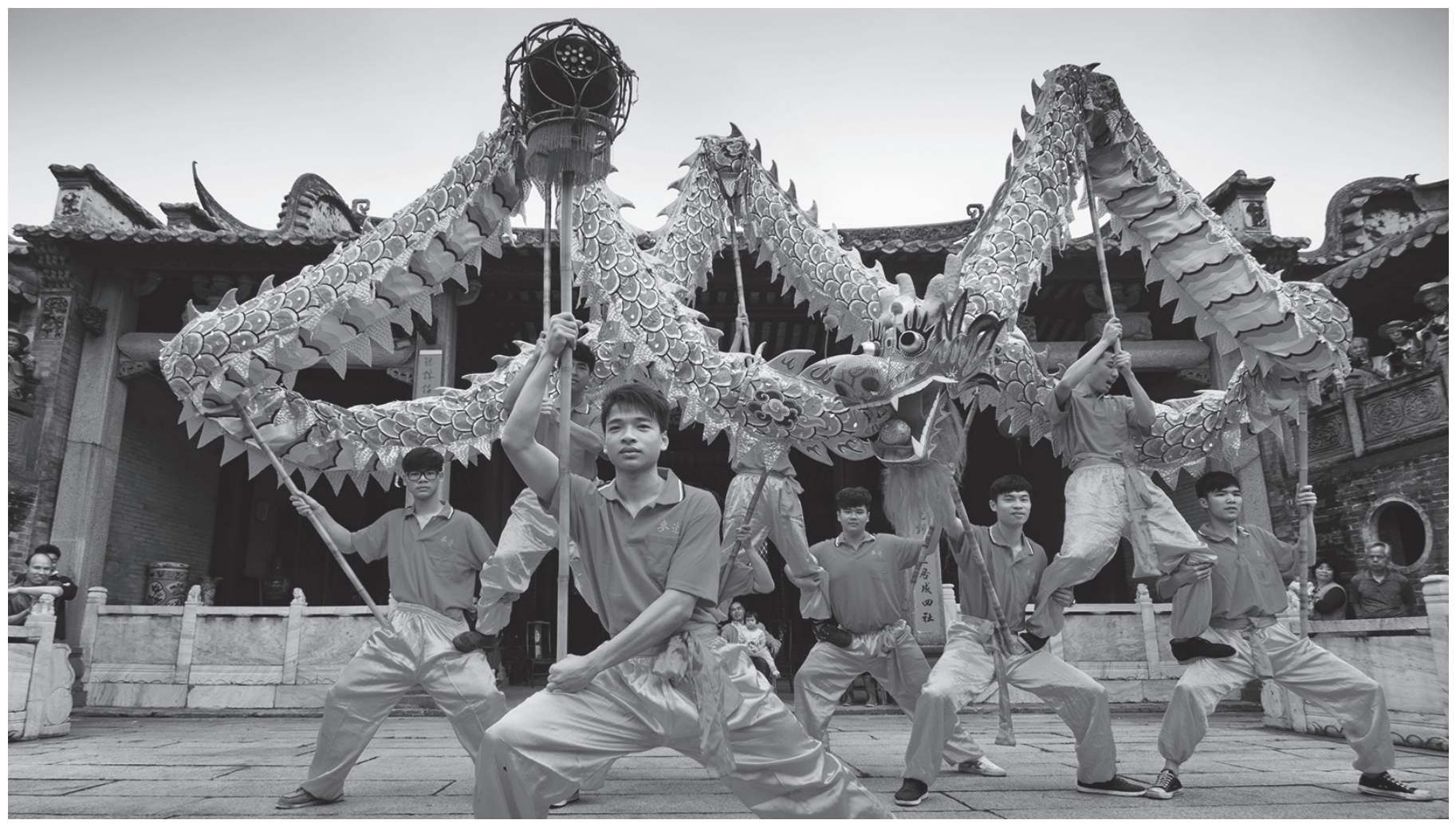




\section{El buen juez por su casa empieza}

Antes de que el milagro chino fuera estudiado y analizado de manera sustancial a finales del siglo $\mathrm{Xx}$, ALC ya contaba con sendos desequilibrios económicos a nivel macro y microeconómico, situación que justificó el cambio de paradigma económico para que de manera generalizada el ahora modelo de libre mercado se impusiera teniendo como piedra angular el Consenso de Washington mismo que fue el parteaguas para una serie de reformas estructurales que al día de hoy en países como México están terminando por desmantelar toda el aparato institucional que permitió al menos entre 1950 y finales de los 70's del siglo xx contar una relativa estabilidad económica y social.

La presencia de China no vino más que a evidenciar el talón de Aquiles de la estructura productiva nacional y local ya que nunca se pudo modernizar y preparar a los distintos sectores y ramas productivas para hacer frente a la competencia internacional. A ello se suma que a nivel mundial comenzó a configurarse una mayor especialización económica a nivel regional comandada por el capital en sus diversas formas (financiera, comercial, industrial). Situación determinante para que al interior de los países, principalmente aquellos en vías de desarrollo no pudieran continuar con sus propios procesos de crecimiento en el área agropecuaria, industrial y de servicios. En su lugar lo que se está observando es un retroceso en los renglones antes mencionados ya que en aras de solventar un propio modelo de crecimiento, se atiende la demanda internacional renunciando con ello a una estrategia nacional horizontal pues sólo se beneficia a unas cuantas ramas y empresarios.

Se ha responsabilizado a China de que sus productos de baja calidad y "piratas" y su creciente presencia a través de comercios al menu- deo son motivo del quiebre de empresas locales y familiares en el terreno textil, plásticos y juguetería, medicinas y cosméticos, software, etc. En efecto este tipo de productos generan este resultado pero también es menester señalar que las condiciones nacionales propician que tal fenómeno se reproduzca tal Hidra de Lerna.

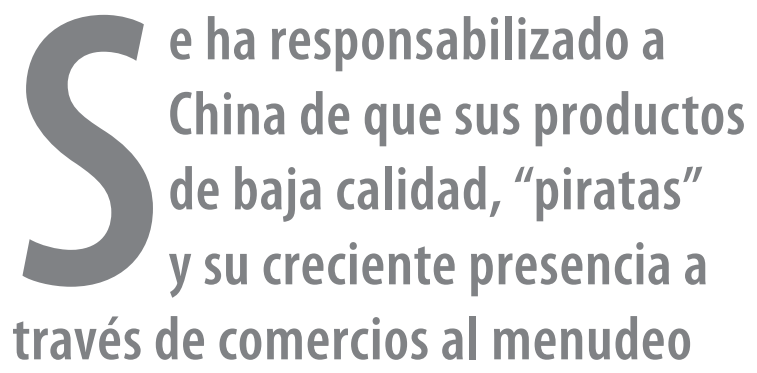
son motivo del quiebre de empresas locales y familiares en el terreno textil, plásticos y juguetería, medicinas, cosméticos y software

Primero, en casos como México donde el poder adquisitivo del salario no permite adquirir los satisfactores básicos (alimentación, vestido, salud, etc.) y el tamaño de la población en distintos niveles de pobreza asciende a poco más del $50 \%$ de la población total, hace que el consumo y venta de productos chinos apócrifos y de baja calidad se convierta en un mecanismo de subsistencia económica y social.

Segundo, las condiciones competitivas de las empresas nacionales al ser limitadas no pueden siquiera producir este tipo de productos. ${ }^{1}$

1 México por ejemplo no puede competir con China en la rama de plásticos basados en moldes de precisión para inyección debido a que sólo utiliza métodos tradicionales de electro erosión maquinado. Esta diferencia de métodos marca la producción intensiva de productos y piezas de plástico empleados por ejemplo en la industria automotriz, juguetera, electrónica, etc. 
Menos aún de aquellos de mayor valor agregado, de mediana y alta tecnología. La diferencia también radica en que sean productos de alta o baja calidad que incluso cuentan con la venia del Estado chino. Regiones enteras se especializan en ello y cuentan con las condiciones laborales, ambientales e industriales necesarias. ${ }^{2}$

Tercero, la entrada de estos productos a territorio latinoamericano y especialmente a México cuenta con el visto bueno de autoridades aduanales, judiciales y de los propios gobiernos locales. En distintas partes del territorio mexicano es posible identificar claramente centros comerciales y en las calles todo un universo de productos chinos de diversa índole (legales e ilegales).

La primera conclusión que presentamos en este momento es que si deslindamos responsabilidades, China no es el responsable de que ALC y México tengan un saldo deficitario en su balanza comercial a nivel agregado y de que en lo sectorial el impacto implique la desaparición de ramas y cadenas productivas. Por un lado está la labor que deberían hacer organismos internacionales tales como la Organización Mundial de Comercio pero particularmente es cada país quien debe articular planes nacionales de desarrollo para impulsar la producción y consumo interno antes que satisfacer la demanda externa.

\section{Sin recetas para el crecimiento económico}

Dentro de la economía como disciplina se ha desarrollado un cuerpo analítico de teorías del crecimiento, mismas que parten de modelos y supuestos para explicar cómo y bajo qué me-

2 Se considera que a raíz de que China cumpla formal y sistemáticamente con los requerimientos de la Organización Mundial de Comercio, la violación de patentes y derechos de autor disminuirá la producción de productos apócrifos.

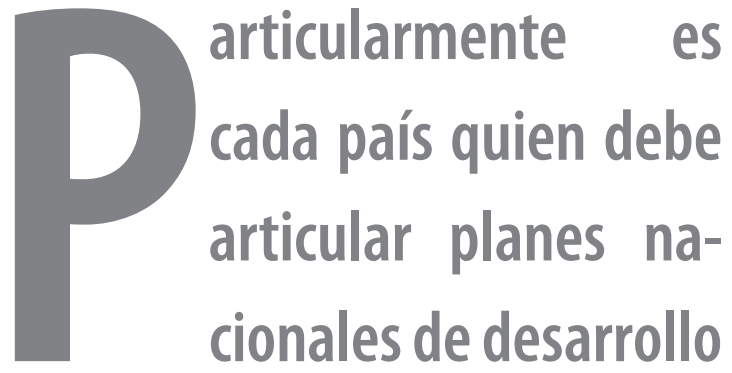

para impulsar la producción y

consumo interno antes que satisfacer la demanda externa

canismos podría impulsarse el crecimiento del PIB, el cual se interpreta como el principal detonante para salir del atraso y alcanzar el desarrollo. Ya en lo concreto todos los modelos son la base para diseñar políticas, estrategias y acciones en materia educativa, tecnológica, fiscal, monetaria, laboral, etc., que se supone determinarán el rumbo de la dinámica nacional. Desde un punto de vista pragmático se afirma que cada país fija su propia ruta sin embargo, ya en la realidad pocos lo pueden lograr puesto que se imponen otras fuerzas que condicionan en buena medida la toma de decisiones y de cada proyecto de crecimiento nacional. Interviene como ya se mencionó: el contexto histórico y geográfico, la situación mundial vigente y la posición que se juega dentro del sistema político-económico mundial.

En su momento el desarrollo de países como Francia, Inglaterra, Estados Unidos o Alemania fueron la base de estudio para connotados economistas como Simon Kusnetz para explicar que su éxito consistió entre otros aspectos en una serie de factores fundamentales siendo estos: la consolidación de instituciones, el desarrollo tecnológico e industrial, 


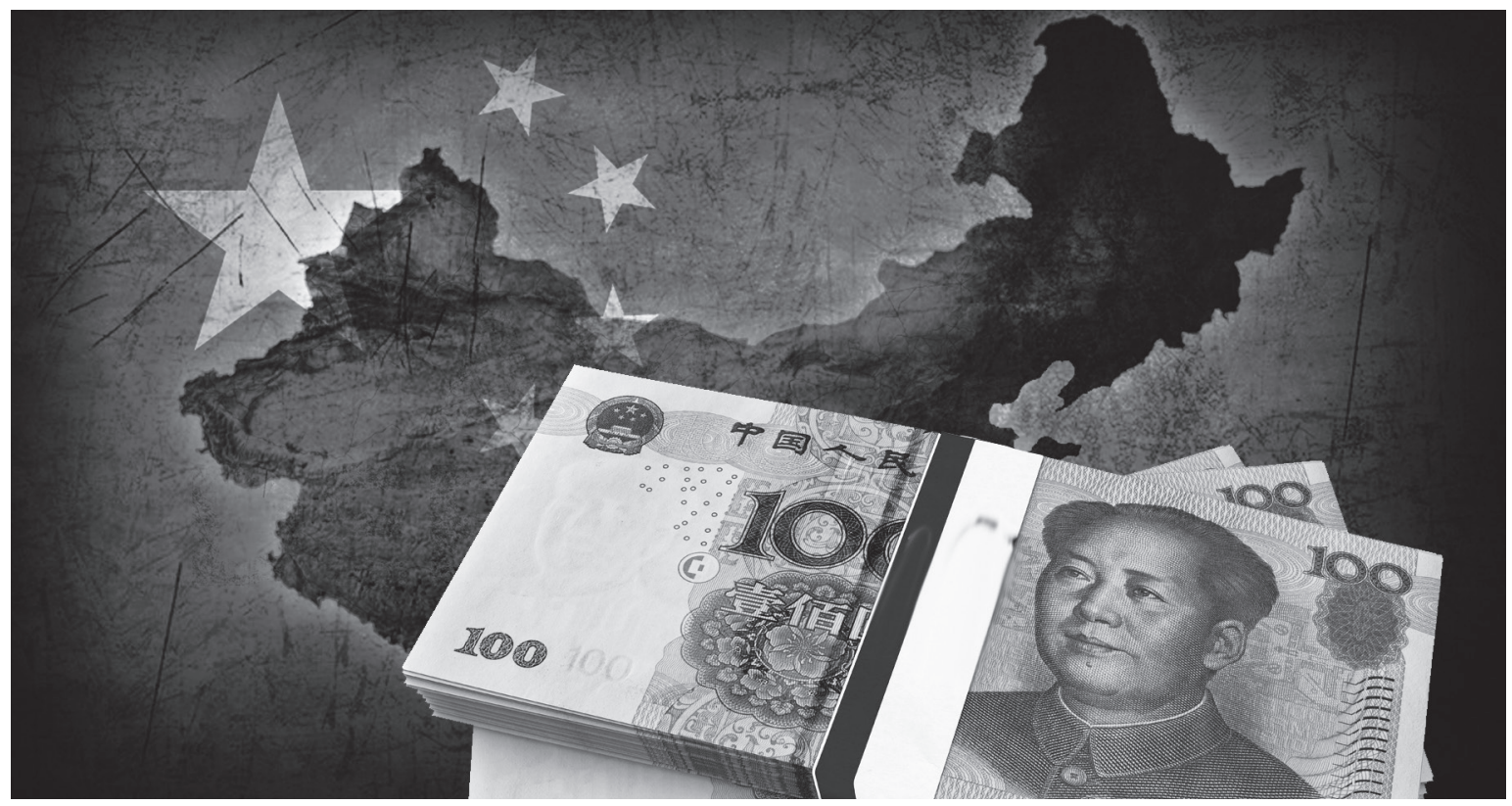

el cambio de valores sociales, el control demográfico, la administración del espacio urbano y los cambios de la organización económica, (Kusnetz, 1970). Posterior a la caída del keynesianismo y con el modelo de libre mercado en todo su esplendor, en casi todas las economías del planeta se han seguido al pie de la letra los postulados del Consenso de Washington y una segunda serie de reformas denominadas de "segunda generación", (Rodrik, 2011: 37). Sin embargo, los resultados en un periodo de 30 años distan mucho de lo que el discurso original pregonaba acerca de mejorar las condiciones de vida de millones de habitantes sobre todo en ALC debido a que los resultados pueden catalogarse como negativos: tasas de crecimiento del producto bajas, pobreza creciente, etc.

Dentro de este contexto China viene a irrumpir con su propia interpretación y aplicación de políticas rompiendo con ello el mainstream económico de que el Estado debe limitar su participación en la actividad económica y social. El propio Rodrik de manera didáctica expone en su obra "Una economía, muchas recetas" (2007), que hasta un marciano estaría confundido por el hecho de que mientras China hizo todo lo contrario a dicho Consenso, su producto creció durante tres décadas en promedio $10 \%$ a diferencia de ALC. Tal exposición sirve para explicar que China al igual que otros países del sudeste asiático se ha valido de mecanismos que controlan lo económico bajo el Estado aun con la presencia de capitales extranjeros, (Ibídem, 47). Arrighi cita al respecto:

"El gobierno chino dio la bienvenida a la inversión directa extranjera, pero también en este caso en la medida en que entendía que servía al interés nacional chino. Así a principios de la década de 1990 se les dijo a Toshiba y otras grandes empresas japonesas, en términos bastante tajantes, que a menos que aportaran consigo a sus fabricantes de componentes, no serían bien recibidos. De esta forma es que se establecen consorcios simultáneos rivales con sociedades extranjeras, como lo hicieron los Automóviles de Guangzhou con Honda y Toyota, algo que Toyota no había aceptado en ningún otro país" (Arrighi, 2007: 370). 
De lo anterior, es importante señalar que el éxito económico chino suele ser explicado predominante a través del análisis económico neoclásico para destacar la importancia de la industria, las instituciones, la inversión extranjera directa, el desarrollo de la ciencia y tecnología, la industria así como el comercio exterior entre otros aspectos. Si bien no es erróneo, puede llegar a ser reduccionista por centrarse en analizar determinadas variables y su comportamiento. A esto hay que sumar que desde la postura neoclásica escapa lo político, lo ambiental y lo social como elementos dinámicos y que no responden a los estímulos del mercado.

Desde una perspectiva heterodoxa no se trata de explicar solamente el crecimiento del producto sino de todo el proceso de acumulación en su conjunto. Por esta razón para aquellos que buscan en el caso chino elementos que pudieran trasladarse a la realidad latinoamericana sin conocer el universo de medidas establecidas por el gobierno chino desde la era maoísta, están cometiendo un enorme error interpretativo. En este sentido, hay una serie de políticas que han trastocado significativamente a diversas generaciones de habitantes chinos en sus valores y reproducción social. De tal suerte que medidas de control demográfico y migratorio como el Hukou y la política del hijo único (hoy ya eliminada), serían impensables en ALC. A ello se suma el férreo control de la información y de sus distintas formas de expresión, el cual es comúnmente denunciado desde occidente y por los propios disidentes chinos exiliados en el extranjero o por presos político al interior de China, (Li, 16/12/13). El ascenso de China a decir de Harvey, se debe a la construcción de un particular tipo de economía de mercado que combina elementos del neoliberalismo con control centralizado autoritario para aplicar todo lo establecido dentro de los planes quinquenales, es decir, un neoliberalismo con características chinas, (Harvey, 2005: 120).
China no puede ser un ejemplo de crecimiento para ALC por los altos niveles de explotación y las condiciones bajo las que es sometida el promedio de la fuerza de trabajo. Empresas nacionales y trasnacionales cuentan con un escenario inmejorable dentro del territorio chino en materia laboral para asegurar altas tasas de rentabilidad. Ello sin contar la devastación ambiental que están sufriendo a lo largo y ancho de su territorio y que repercute negativamente en lo social y lo ecológico. Aquellos pasajes que describen K. Marx y F. Engels en El Capital, sobre la clase obrera y la forma en que es sometida y explotada en las fábricas y centros urbanos de la Europa del siglo XVIII y XIX pareciera se plasman a la perfección en la China del siglo XxI.

"Cuanto más rápidamente se acumula el capital en una ciudad industrial o comercial, tanto más veloz es la afluencia del material humano explotable, tanto más míseras las improvisadas viviendas de los obreros. "Newcastle-uponTyne", como centro de un distrito carbonífero y minero cuyo rendimiento es cada vez mayor, ocupa, después de Londres, el segundo puesto en el infierno de la vivienda. No menos de 34.000 personas viven allí en viviendas de un solo cuarto", (Marx 1867: 825).

"Las casas en que suelen vivir los obreros están situadas en pasadizos y patios estrechos. En lo tocante a luz, aire, espacio y limpieza, esas casas son verdaderos modelos de insuficiencia e insalubridad, una vergüenza para cualquier país civilizado. Hombres, mujeres y niños yacen revueltos en ellas durante la noche. En cuanto a los hombres, el turno de la noche sucede al del día en una secuencia ininterrumpida, de tal manera que las camas casi no tienen tiempo de enfriarse. Las casas están mal provistas de agua y peor aún de letrinas, son inmundas, mal ventiladas, pestilentes", (ibídem). 
Escenarios como estos se reproducen en los espacios urbano-industriales y particularmente en las zonas económico especiales. Hay estudios que se han realizado para documentar que los métodos de generación de plusvalor absoluto y relativo en las ramas textil, electrónica o la automotriz asemejan a lo citado por Marx.

Las asociaciones DanWatch y China Labor Watch en el año 2013 elaboro el trabajo "Electrónica low cost: Estudio de las condicio-

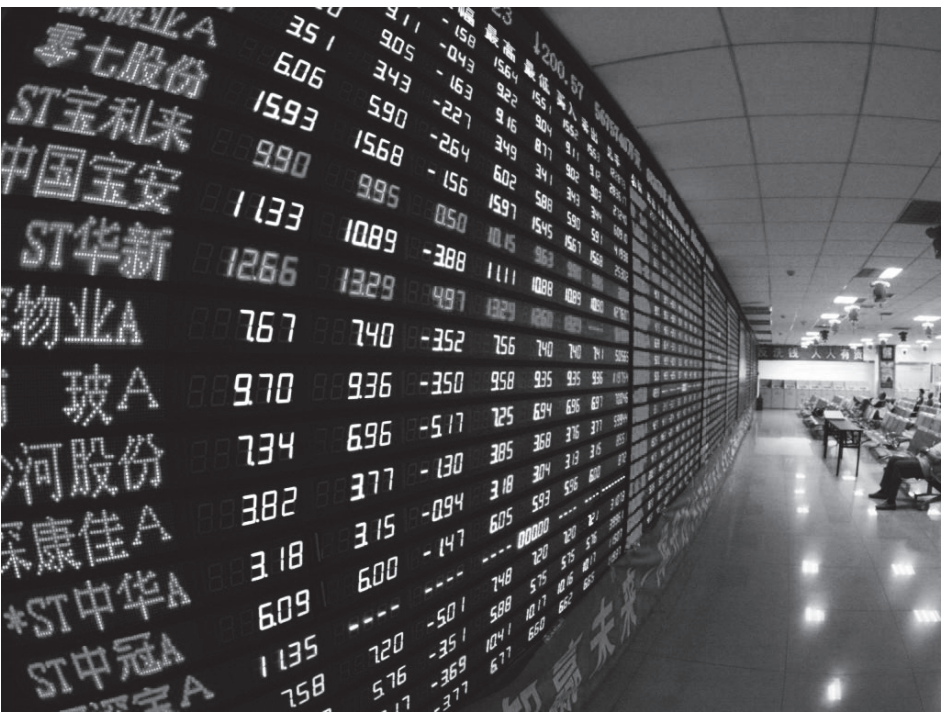
nes laborales de cuatro proveedores de Dell en China". En esta obra se analizan los mecanismos de explotación de la fuerza de trabajo china en cuatro de las fábricas Mingshuo (Jiangsu), Hipro Electronics, Msi y Taida (Guangdong) ${ }^{3}$ que son proveedoras de la empresa de productos electrónicos de la firma estadounidense Dell.

3 Mingshuo es una filial del grupo taiwanés Pegatron dedicada a la producción y ensamblaje de componentes de informática y accesorios para ASUS, HP, Samsung, Microsoft y Dell. La fábrica de Suzhou es la más grande de la provincia (158.000 metros cuadrados) y emplea a unas 70.000 personas en épocas de puntas de trabajo y a unas 50.000 en temporada baja.

Hipro Electronics forma parte de Chicony Power Technology, una filial del grupo taiwanés Chicony. Produce fuentes de alimentación conmutadas y otros aparatos electrónicos destinados exclusivamente a la exportación para Microsoft, IBM, HP, Samsung, Compaq, NEC, Yokogawa, Sony y Dell. Emplea a 6.000 personas.

MSI, empresa taiwanesa con fábricas en China. El complejo industrial de Shenzhen (200.000 metros cuadrados de superficie y 8.000 puestos de trabajo) se dedica a la producción y ensamblaje de componentes de informática, como placas base, tarjetas gráficas, tarjetas de memoria flash y otros accesorios. MSI posee una línea propia de productos y también fabrica para las grandes marcas, como HP, NEC y Dell.

Taida Electronics es una filial del grupo Delta Electronics. El complejo industrial de Dongguan está formado por cinco fábricas que ocupan 126.700 metros cuadrados, emplean a 30.000 personas y se dedican a

Los casos antes expuestos apenas y son una mínima muestra del amplio espectro de centros fabriles que existen en China. Si bien el gobierno chino argumenta que existen reglamentaciones y leyes para regular a las empresas, la realidad evidencia lo contrario. Máxime cuando el propio gobierno es renuente para dar conocer a fondo las condiciones laborales de los obreros chinos y de los centros de trabajo.

China al igual que cualquier otro país capitalista está experimentando por un lado una brecha creciente entre el ingreso urbano y rural $y$, especialmente el incremento de la concentración de la riqueza. En la gráfica 2 se observa como el coeficiente de Gini paso de 0.345 en 1990 a 0.470 en 2010, pese a ello en una lógica Kusnetsiana el gobierno argumenta, que esto es natural y sólo se trata de una transición hacia el desarrollo tal y como lo experimentaron las grandes potencias mundiales, donde al principio se observan tasas de crecimiento y concentración del ingreso altas y posterior-

\footnotetext{
la producción de chips, placas de circuitos, fuentes de alimentación conmutadas, cables y adaptadores de alimentación. Es proveedora de NEC, GE, HP, Fujitsu, Phillips y Dell.
} 
Sergio E. Martínez Rivera | China: ioportunidad para el crecimiento económico de México y de América Latina?

mente se pasara a un escenario de crecimiento sostenido con una mejor distribución de la riqueza entre la sociedad.

La pregunta debería ser qué ha hecho ALC y México para que no crezca y mejore su bienestar económico y social, más aun en un contexto donde las restricciones ambientales comienzan a ser cada vez más adversas.

\section{¿Es entonces China la oportunidad de crecimiento que requiere México y ALc?}

La postura ideológica neoliberal estableció que el crecimiento ya no podía tener como asiento la inversión e injerencia del Estado, ello abrió las puertas a la inversión privada nacional y extranjera para posicionarse donde le resultara más redituable y también marcó la pauta para que el crecimiento (al menos en el discurso) estuviera basado en el comercio exterior. Desde entonces prácticamente casi todos los países de ALC apegados a este designio mundial han apostado sus activos naturales y sociales para responder a la demanda internacional. Los territorios nacionales por su parte se han súper especializado y subordinado para cumplir con compromisos suscritos entre los gobiernos centrales y las empresas nacionales y transnacionales.

Bajo este escenario se insiste en que China y la economía mundial es la panacea para encausar el crecimiento en las economías latinoamericanas sin embargo, el discurso oficial evade discutir las condiciones estructurales bajo las que actualmente se encuentra ALC y son en sí su principal obstáculo. Los sectores empresariales, académicos, políticos y sociales más optimistas ven en China la oportunidad para subirse al "tren de la prosperidad" sin dimensionar y cuestionar hasta donde es viable no sólo económica sino también social y ambientalmente.

No existen indicios para suponer que China en el corto y mediano plazo impulse el crecimiento económico integral que requiere ALC. Lo que si se observa es que sólo los sectores y ramas exportadores así como los importadores de productos de demanda final al mayoreo y menudeo son los que están teniendo mayores beneficios. La expectativa de penetrar de manera masiva al mercado chino con productos

\section{Gráfica 2}

Evolución del coeficiente de Gini en China, 1990-2010

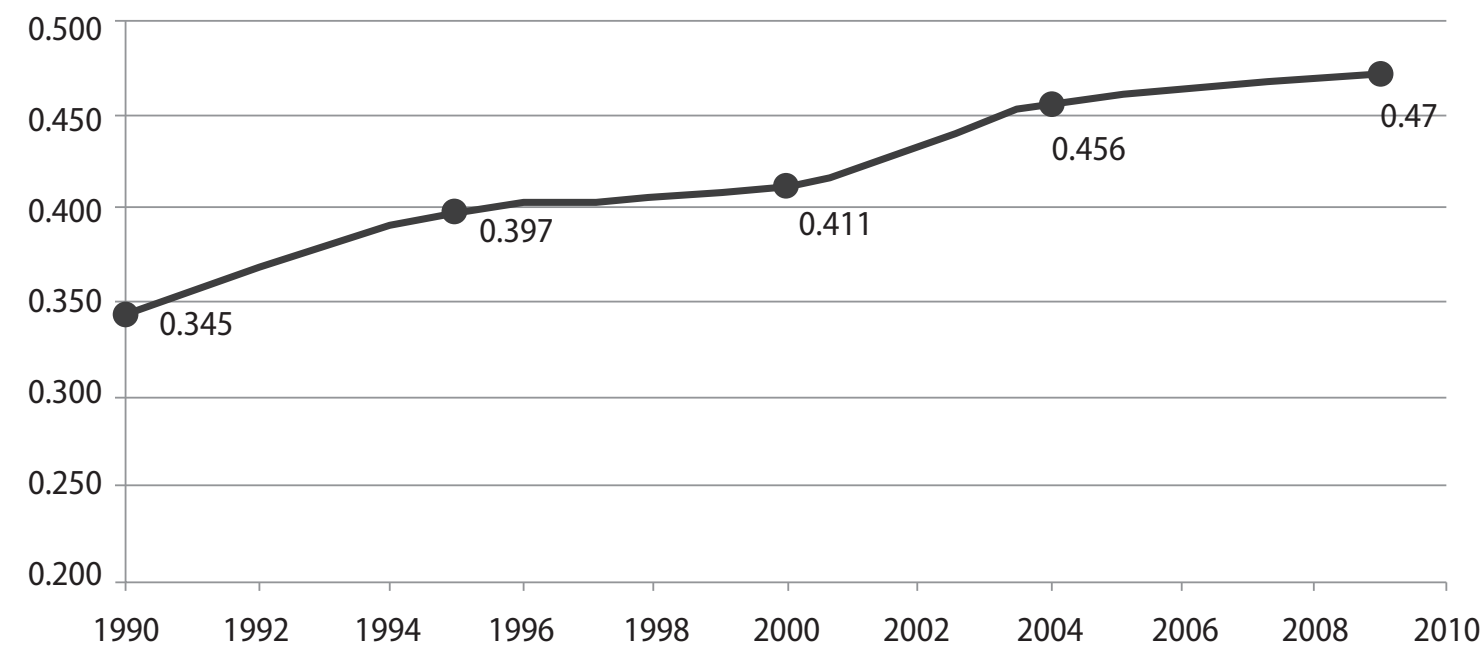

Fuente: Instituto español de banca y comercio, 2011. 


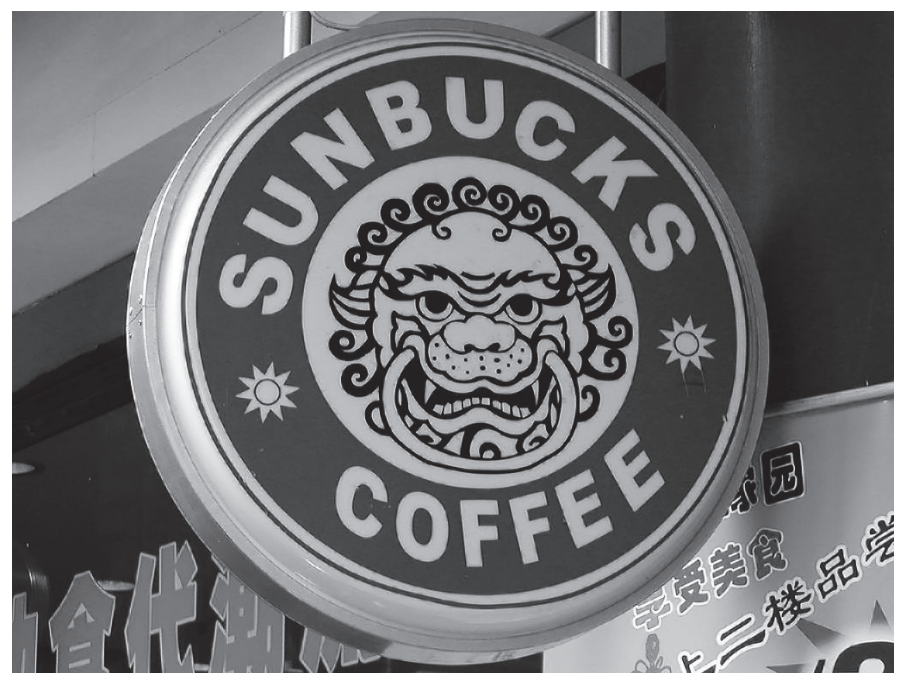

reconocidas no sólo mundialmente sino también recomendadas por los propios sectores que ya han consumido los propios productos.

A finales del año 2010 y ahora en el 2016 el gobierno chino emitió su política de Estado para ampliar la relación con ALC en cuatro grandes áreas: política, económica, cultural y social y, paz, seguridad y justicia. En el discurso el gobierno chino proyecta que con dicha estrategia, ambos bloques se beneficiaran paulatinamente en el mediano y largo plazo. No obstante,

de demanda final tampoco se observa que en el corto plazo se puedan concretar. Es complicado aún para las grandes empresas transnacionales posicionarse, no sólo por las restricciones institucionales y condicionamientos que imponen las autoridades chinas. Sino también porque el propio mercado interno está en un proceso de consolidación hacia la occidentalización y que el propio gobierno trata de impulsar. Es decir, en este momento la población promedio china posee uno de los niveles de ahorro más alto a nivel mundial (25 a 30\%) pero no practica el crédito consuntivo tal y como se puede observar en occidente; ambos, factores limitan que el consumo doméstico no sea como sucede en otras economías americanas o europeas.

El consumidor promedio chino es sui generis ya que prefiere marcas nacionales antes que extranjeras; los productos además de cumplir con las reglamentaciones estatales enfrentan la idiosincrasia popular como las supersticiones. El mercado boyante al que hacen referencia los entusiastas emprendedores es la llamada nueva "clase" media urbana, también representa un fuerte reto para las empresas extranjeras ya que no consume cualquier marca comercial a pesar de las intensas campañas de publicidad que puedan existir. Deben ser marcas de prestigio, se percibe que si bien dicha política es aparentemente transversal, ALC seguirá ocupando un lugar tangencial para China ya que por ejemplo, no quiere aceptar tratados de complementariedad productiva. Su principal objetivo seguirá siendo alrededor de suscripción de proyectos en infraestructura para la explotación de recursos naturales (puertos y carreteras), invertir en sectores estratégicos como la minería y energía y seguir impulsando las exportaciones de productos primarios y semi procesados basados en cobre, hierro, etc.

\footnotetext{
"América del Sur suministra, más del 60\% de las importaciones chinas de soja, principalmente desde Brasil y Argentina; $80 \%$ de harina de pescado, desde Perú y Chile; cerca de 60\% de despojos de aves troceados, desde Argentina y Brasil; y $45 \%$ de vinos y uvas, de Chile. Por otro lado, la canasta exportadora de los países de esa subregión se concentra en un número bastante reducido de productos. En el caso de Argentina, por ejemplo, tres productos (semillas de soja, aceite de soja y petróleo) constituyen más del $84 \%$ de sus exportaciones totales hacia la RPCh. Un caso similar es el de Chile, donde tres productos (cobre refinado, concentrado de cobre y pulpa de madera) constituyen el $85 \%$ de sus exportaciones totales al país asiático", (Rosales, 2007).
} 
Sergio E. Martínez Rivera | China: ioportunidad para el crecimiento económico de México y de América Latina?

\section{Gráfica 1}

Distribución porcentual acumulada de la inversión directa china en el mundo, 2009

América

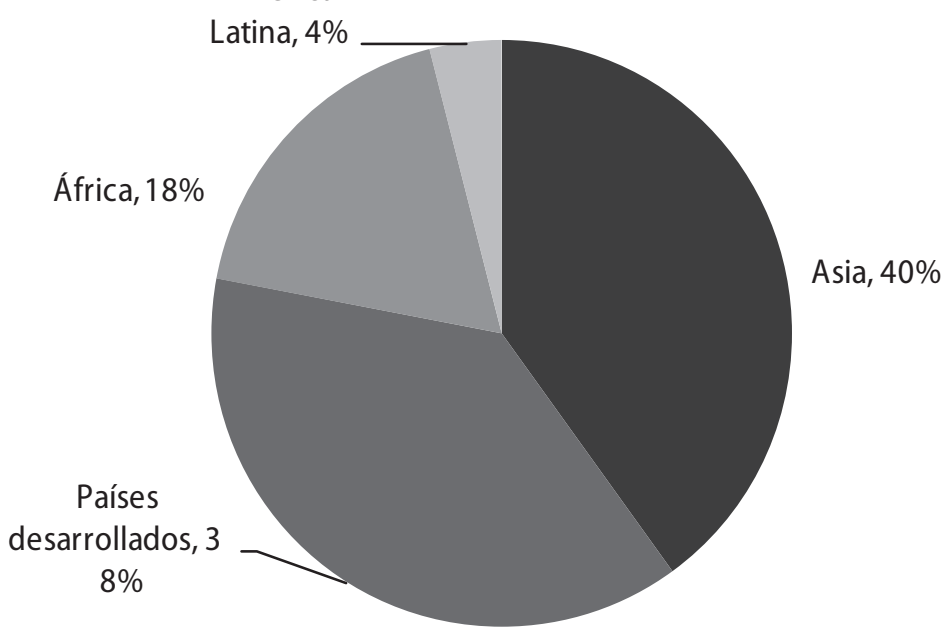

Fuente: Comisión Económica para América Latina y el Caribe (CEPAL), sobre la base de Ministerio de Comercio de China. "2009 Statistical Bulletin of China's Outward Foreign Direct Investment", 2010.

Más aun, desde que en el año 2013 el gobierno chino anunció la llamada "nueva normalidad china" que es una medida para reorientar y desacelerar el crecimiento del PIB se estima que la demanda de bienes y servicios provenientes de ALC disminuirán. Situación que afectara inevitablemente el llamado boom de materias primas y con lo que los ingresos obtenidos por este rubro descenderán para la región (OCDE, 2015).

En otro sentido, para China, ALC es menos relevante en términos económicos que como lo señala Jenkins “... tomando a América Latina y al Caribe en su conjunto, la región representa solamente el 3\% de las exportaciones de China, y el 3,8 de sus importaciones. Por otro lado, China es uno de los cinco primeros mercados de exportación para Argentina, Brasil, Chile, Cuba y Perú, y es una de las cinco fuentes principales de las importaciones de estos países, así como de Colombia, México, Paraguay y Uruguay" (Jenkins, 2009: 253). Del mismo modo obsérvese el volumen de la inversión directa china colocada a nivel mundial. Así, mientras que del 100\% de la inversión acumulada al 2009, Asia ha recibido el 40\%, distintos países desarrollados (Estados Unidos, Canadá, Espańa, etc.) el 38\%, África el $18 \%$ y AL, se encuentra al último con el 4\%. Ver gráfica 1.

En suma, China parece más una oportunidad de negocios sectoriales que una oportunidad de crecimiento integral para ALC y sus distintas regiones. Sobre este aspecto también debe mencionarse que cada país latinoamericano ha impreso su propia estrategia aunque al final redundan en lo ya señalado exportar materias primas y productos semi procesados e importar mercancías chinas. Unos con diferente saldo en la balanza comercial pero en la misma tesitura.

México por su parte parece seguirá anclado con su relación histórica con los Estados Unidos la cual esta tambaleándose con la llegada de D. Trump en renglones como el de la renegociación del Tratado de libre Comercio. Urge que el gobierno de México reconsidere toda su política económica y su dependencia con la economía norteamericana ya está perdiendo terreno en este mercado frente a China 
en diversos sectores y ramas como la eléctrica, la automotriz y otros productos manufacturados (Dussel Peters, 2013: 13-24).

\section{Conclusiones}

El ascenso de China está jugando un papel central en la reconfiguración política y económica mundial pero aún debe resolver varios retos para aspirar a ser una potencia desde un punto de vista progresista en lo social, económico, ambiental. La parte social no sólo debe atenderse satisfaciendo el poder adquisitivo de la población y disminuyendo los niveles de pobreza (de por sí significativo) sino más aun propiciando una mayor equidad entre lo urbano y lo rural y sobre todo, atendiendo el tema de los derechos humanos universales: civiles y políticos, económicos, sociales y culturales. ${ }^{4}$

El tema ambiental es igual de complejo, debido al alto crecimiento económico que ha registrado China, la demanda de bienes y servicios ambientales ha sido intensiva al igual que la generación de residuos y desechos. Lo cual afecta no sólo al territorio chino sino al resto del mundo ya que los países (principalmente aquellos en vías de desarrollo) en su afán de vincularse con China están comprometiendo sus ecosistemas para satisfacer la demanda de energía, minerales, cereales y granos, madera, recursos marinos y materias primas en general. Dicho modelo es cuestionado ya desde los 50's con la Teoría de la dependencia por no aportar al crecimiento económico de los países (en este caso de ALC) de manera integral. Por el contrario, en la actualidad es insostenible este patrón de exportaciones basado en productos prima-

4 Para conocer con amplitud el listado de los derechos humanos universales consultar: http:// www.derechoshumanos.net/derechos/index. htm?gclid=Cl7Fw-XXq8QCFZKLaQodtOYAwA rios y semi transformados por devastación ambiental que ello genera y porque no resuelve las condiciones de atraso regionales.

Atendiendo la pregunta que da lugar a este ensayo acerca de si China es realmente una oportunidad de crecimiento para ALC y México, la evidencia demuestra que no bajo el actual modelo desarrollado entre ambas regiones. Es verdad que se obtienen ingresos y beneficios pero no para motivar un efecto multiplicativo en el producto nacional. Esto se comprueba aun en países que sostienen un tratado de libre comercio con China como Costa Rica, Perú y Chile.

Ante este escenario se debe repensar el modelo completo en que está sumida ALC. La obcecación de atraer inversión extranjera para impulsar el crecimiento del producto ya está demostrado a lo largo de tres décadas no ha resultado un método eficiente. Lo que China al igual que otros países asiáticos ofrece como principal lección es que las empresas trasnacionales así como la inversión extranjera deben estar apegadas a las rutas y criterios que el Estado establece para atender las necesidades más apremiantes de cada país. Se debe re explorar una propuesta de impulsar la producción nacional y atender el mercado interno y, particularmente disminuir la concentración del ingreso.

El Consenso de Washington y el modelo de libre mercado en su conjunto ya demostraron estar agotado. Sin embargo, sigue defendiéndose por grupos políticos y económicos

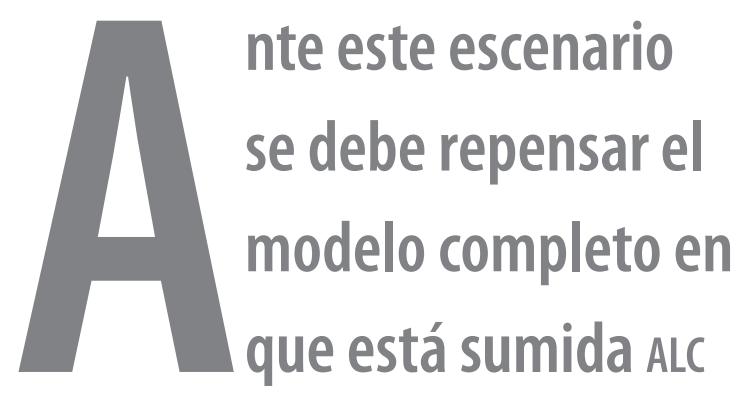


oligárquicos pues ha resultado propicio para sus propios intereses y cumplir así con el orden mundial establecido.

Detrás de China viene la India otra economía emergente y que por el momento escapa de toda la parafernalia que se ha construido alrededor del fenómeno chino por ciertos sectores de políticos, empresarios, académicos y la propia sociedad. Se debe regresar a los planteamientos estructuralistas incluyendo dentro de la discusión el significado de la globalización. Más aun cuando se atribuye a que el fracaso económico de los países en vías de desarrollo se debe a una mala estrategia de incorporación. No se trata de cerrar fronteras e instaurar un proteccionismo a ultranza como antaño pero tampoco como lo hicieron países como México que de nada le vale estar entre los primeros lugares de los países que más exportan al mundo y con un amplio número de tratados y convenios con el exterior, donde el comercio exterior juega una pieza preponderante.

Por cuestiones geográficas, de mercado y disponibilidad de recursos naturales sería más conveniente impulsar proyectos de desarrollo regional entre México, Centro y Sudamérica que centrar toda la atención hacia China, pero no desde una perspectiva donde deben ser comandados por el Fondo Monetario Internacional, el Banco Mundial y las grandes empresas transnacionales.

La realidad actual de ALC exige un escenario de mayor trascendencia. El ideal de crecimiento debería ser entonces de manera horizontal y reflejada en mejores condiciones para la sociedad. No a la inversa, mayor rentabilidad para la clase empresarial basada en la desigualdad y la concentración del ingreso.

Finalmente, en este tipo de discusiones deben incluirse planteamientos de otras corrientes que cuestionan el postulado ortodoxo del crecimiento. Existen reflexiones sobre el llamado decrecimiento, desarrollado por Serge Latouche, quien parte de que debe controlarse la producción económica con el objetivo de alcanzar una nueva relación de equilibrio entre el ser humano y la naturaleza. Por ello es que ninguna propuesta es ociosa o utópica cuando está demostrado que los modelos de crecimiento de mayor envergadura en el siglo xx no han resuelto contradicciones históricas entre los países del centro y la periferia. 


\section{Bibliografía}

Arrighi, Giovanni. 2007. Adam Smith en Pekín: Orígenes y fundamentos del siglo XXI. Ed. Akal, España.

DanWatch y China Labor Watch (2013). Electrónica low cost: Estudio de las condiciones laborales de cuatro proveedores de Dell en China. http://www. setem.org/media/pdfs/Informe_Electronica_low_ cost_CAST.pdf consultado el 31 de marzo de 2014.

Dussel, Peters Enrique et al. (2013). China and the New Triangular Relationships in the Americas. China and the Future of US-Mexico Relations. CLAS-University of Miami, CLAS-University of California and CECHIMEX, FE-UNAM.

Instituto espańol de Banca y Comercio, 2011. El XII Plan Quinquenal de China. España.

Harvey, David. 2005. Brief History of Neoliberalism. Oxford. University. Press. UK.

Jenkins, Rhys. 2009. El impacto de China en América Latina en Revista CIDOB D'AFERS INTERNACIONALS, No.85-86. Barcelona, España.
Kuznets, Simon. 1970. Crecimiento Económico y Estructura Económica. Ed. Gili, España.

Li, Jianhong. 16/12/2013. "El pueblo chino ha pagado un alto precio por el despegue económico". Consultado el 12 de marzo de 2015 de:

https://www.es.amnesty.org/noticias/entrevistas/entrevista/articulo/li-jianhong-el-pueblo-chino-hapagado-un-alto-precio-por-el-despegue-economico/

Martínez, Rivera Sergio E. (2013). China y América Latina y el Caribe: una visión ambiental heterodoxa de su intercambio comercial en Trápaga, Yolanda (coord.), América Latina y El CaribeChina: Recursos Naturales y Medio Ambiente. RED ALC-CHINA, UDUAL y CECHIMEX, FE-UNAM.

OCDE. 2015. Perspectivas económicas de América Latina, 2016: hacia una nueva asociación con China.

Rosales Osvaldo y Mikio Kuwayama. (2007). América Latina al encuentro de China e India: perspectivas y desafíos en comercio e inversión. Revista de la CEPAL no. 93. Chile. 